\title{
Corpo, gênero e imagem: desafios e possibilidades aos estudos feministas em educação
}

Gregory da Silva Balthazar Fabiana de Amorim Marcello'

\section{RESUMO}

Neste artigo, problematizamos os modos pelos quais o conceito de imagem vem sendo debatido, hoje, no seio dos estudos de gênero em educação. Para tanto, metodologicamente, da produção do Grupo de Trabalho (GT) 23 - Gênero, Sexualidade e Educação da Associação Nacional de Pós-Graduação e Pesquisa em Educação (ANPEd), de 2003 a 2015, analisamos os trabalhos que elegem a imagem como central, atentando para o modo como eles operam com esse conceito, instituindo-o sob os marcos do que chamamos de uma imagem-saber. Discutimos como a imagem, construída como instrumento que educa nossos corpos, acaba por instituir-se como uma ferramenta decisiva para o debate sobre as pedagogias de gênero e sexualidade, mas, ao mesmo tempo, para a construção e o fortalecimento de uma espécie de mistica feminina contemporânea. Por fim, sugerimos, com a ajuda de autores como Didi-Huberman e Butler, outras relações teórico-metodológicas com as imagens, problematizando-as no lugar de onde nos convidam a criar outros modos de viver o gênero e a sexualidade.

PALAVRAS-CHAVE

corpo; gênero; imagem.

'Universidade Federal do Rio Grande do Sul, Porto Alegre, RS, Brasil. 


\title{
BODY, GENDER AND IMAGE: CHALLENGES AND POSSIBILITIES TO FEMINIST STUDIES IN EDUCATION
}

\begin{abstract}
In this article, we discuss the ways in which the concept of image is being debated today, within gender studies in education. To do so, methodologically, from the production of GT 23 - Gender, Sexuality and Education of ANPEd, from 2003 to 2015, we analyzed the studies that elect image as central, observing the way they work with this concept, establishing the frames of what we call an image-knowledge. We discussed how the image, built as a tool that educate our bodies, eventually establishes itself as a decisive tool for the debate on the pedagogy of gender and sexuality, but, at the same time, for the construction and strengthening of a kind of contemporary feminine mystique. Finally, we suggested, with the help of authors such as Didi-Huberman and Butler, other theoretical-methodological relationships with images, questioning them in the place from where they invite us to create other ways of living gender and sexuality.

KEYWORDS

body; gender; image.
\end{abstract}

\section{CUERPO, GÉNERO Y IMAGEN: DESAFIOS Y POSIBILIDADES A LOS ESTUDIOS FEMINISTAS EN EDUCACIÓN}

\section{RESUMEN}

En este artículo problematizamos los modos por los cuales el concepto de imagen viene siendo debatido, en los días de hoy, en el núcleo de la crítica feminista en educación. Para eso, metodológicamente analizamos, de la producción del GT 23 - Género, Sexualidad y Educación de ANPED, de 2003 a 2015, los trabajos que eligen la imagen como foco, fijándose en el modo cómo ellos operan con este concepto, instituido bajo marcos que llamamos de una imagen-saber. Discutimos cómo la imagen construida como instrumento que educa nuestros cuerpos, termina por instituirse como una herramienta decisiva para el debate sobre las pedagogías de género y sexualidad, pero, al mismo tiempo, para la construcción y fortalecimiento de una especie de mistica de la feminidad contemporánea. Por último, sugerimos, con la ayuda de autores como Didi-Huberman y Butler, otras relaciones teórico-metodológicas con las imágenes, problematizándolas desde un lugar que nos invita a crear otros modos de vivir el género y la sexualidad.

PALABRAS CLAVE

cuerpo; género; imagen. 
Havia uma estranha discrepância entre a realidade de nossa vida de mulher e a imagem à qual nos procurávamos amoldar, imagem que apelidei de mística feminina [...]. (Betty Friedan, 1971, p. 11, grifos nossos)

Em meados de 1960, a célebre ativista feminista americana, Betty Friedan (1971) trouxe para o debate o conceito mistica feminina - então erigido como uma resposta a um "problema sem nome" que acometia as donas de casa estadunidenses no pós-guerra, cujos "problemas e alegrias de suas vidas [...] simplesmente não se adaptavam à imagem da americana moderna". Naquele momento, há quase 60 anos, a ideia de mística feminina traduzia os diferentes modos de atuação de um modelo de feminilidade sob o qual as mulheres estadunidenses deveriam se conformar: o modelo da modern woman. Nas palavras de Betty Friedan (1971, p. 17-18), o modelo da americana moderna preconizava que "seu papel [da mulher] era procurar realizar-se como esposa e mãe". Emergia daí uma dissonância entre as experiências cotidianas das donas de casa e a mística, que assumia a forma de uma insatisfação com as possibilidades subjetivas então sugeridas e contra as quais essas mulheres precisavam lutar sozinhas.

No período em que Betty Friedan escreveu a obra The Feminine Mystique, as imagens - sejam aquelas da arte pictórica, de uma fotografia em uma revista feminina, de um filme, de um programa televisivo, de uma propaganda ou mesmo da literatura - passavam a ser compreendidas como um elemento decisivo para tornar a mística o "centro querido" e "intocável” (Friedan, 1971) da cultura estadunidense de meados do século XX, sobretudo considerando o que isso representava na construção da própria imagem da família americana e do american way of life. Nessa perspectiva, então, as imagens cumpriam um papel fundamental na manutenção da mística feminina: elas integravam o aparato das redes de saber-poder aí implicados, conformando indivíduos e transformando-os em sujeitos mulheres (e também homens) no interior de um regime de verdade hegemônico. A construção histórica da imbricação entre as imagens e a mística repousou sobre um pressuposto: a mística, por meio das imagens, tornava-se parte dos corpos, limitando as subjetividades. Nesse sentido, e por extensão, podemos dizer que a mística feminista foi, enquanto uma das obras precursoras dos estudos feministas estadunidenses, um dos primeiros movimentos conceituais a questionar o lugar das imagens como um instrumento pedagógico produtor de e produzido em uma cultura política de gênero marcadamente falocêntrica.

Neste artigo, mais do que pensar diretamente sobre o conceito de imagem tal como articulado na obra de Betty Friedan, interessam-nos, singularmente, os desdobramentos dessa aposta sobre o conceito de imagem na produção mais recente 
dos estudos feministas ${ }^{1}$, no campo da educação. Mais precisamente, é, portanto, partindo da ideia das imagens como um instrumento que nos educa dentro da ordem discursiva de uma, talvez, outra mística feminina que desejamos explorar o conceito de imagem que se efetiva no seio da crítica feminista hoje, em nossa área.

Para tanto, nossa argumentação será orientada por três discussões centrais: inicialmente, procuramos apontar - ainda que apenas de forma a situar mais amplamente o caráter histórico da problemática deste texto - para as primeiras aproximações entre os estudos feministas e o conceito de imagem, na tentativa de trazer para o debate os tensionamentos promovidos sobre essa relação pela história da arte feminista. Tal discussão faz-se importante na medida em que, acreditamos, a historiografia estadunidense e inglesa produzida pelas autoras feministas consideradas referências no campo constitui-se, até hoje, como um marco a partir do qual uma compreensão específica sobre a produção do corpo generificado e sexualizado foi efetivada pelas imagens ao longo do tempo - neste caso, prioritariamente, pelas imagens da arte e pelos lugares que os pintores, na qualidade de sujeitos de um olhar masculino, reservaram ao corpo feminino. Em seguida, e buscando mostrar como, atualmente, uma certa noção de mística feminina se encontra não apenas presente, como também fortalecida pelas imagens que permeiam nosso cotidiano - e, com efeito, nossas pesquisas -, analisamos a produção brasileira divulgada na Associação Nacional de Pós-Graduação e Pesquisa em Educação (ANPEd) vinculada ao Grupo de Trabalho (GT) 23 - Gênero, Sexualidade e Educação, desde sua criação, atentando para os trabalhos que, da mesma forma, buscam problematizar a relação entre imagem, gênero e sexualidade. Assim, no caso dos textos da ANPEd, importa-nos discutir como os estudos de gênero e sexualidade em educação vêm travando relações de força com as imagens e, nesse movimento, constituindo-as sob a ordem de uma imagem-saber sustentada a partir dos pressupostos de uma espécie de mística feminina contemporânea. Por fim, e articulando as discussões de Georges Didi-Huberman (nos termos de uma filosofia da imagem) àquelas lançadas por Judith Butler (no que concerne aos marcos - frames - de gênero e sexualidade), buscamos argumentar sobre os efeitos teórico-metodológicos dessa

1 Sublinhamos, desde já, que não tomamos estudos os feministas como mero sinônimo das discussões sobre gênero e sexualidade. Apostamos, antes, na implicação inclusive epistemológica dessa imbricação, como já apontada por Louro (2008). Se entendemos os efeitos do redimensionamento do político empreendido pelos feminismos desde a década de 1960 - ainda que erigidos a partir de marcos teóricos distintos — , claramente percebemos que a incorporação, sobretudo, do conceito de gênero se vincula a uma demanda mais ampla dos estudos feministas. Falamos de uma incorporação que se efetiva, pelo menos, desde a década de 1970 e que responde, em grande medida, a uma demanda histórica do campo, neste caso, ligada à possibilidade de qualificar as possíveis formas de atuação política também por meio do empreendimento de "esforços mais consistentes na produção de conhecimento e desenvolvimento sistemático de estudos que tivessem como objetivo não só reconhecer e denunciar, mas, sobretudo, romper com a homogeneidade e a linearidade com que a subordinação social e a invisibilidade política de mulheres, no plural, vinham sendo tematizadas" (Meyer, 2004, p. 2). Sobre a incorporação do conceito de gênero, em suas distintas abordagens, ao campo dos estudos feministas, ver Meyer (2004). 
associação singular das imagens à ordem do saber. Nossa intenção é debater que o que chamamos de imagem-saber pode contribuir, mas também, em alguma medida, criar desafios para o projeto crítico dos estudos feministas. Assim sendo, menos do que nos restringirmos ao âmbito da imagem-saber, cremos na necessidade de sugerir uma relação outra com as imagens, qual seja, aquela vinculada aos modos como, diante das imagens, podemos ser provocados por um não saber - e, portanto, convidados diferentemente a movimentar (e, por que não, transformar) o que somos enquanto sujeitos de gênero e sexualidade.

\section{UM CORPO SOB O OLHAR MASCULINO}

Pode-se dizer, de certa forma, que, na história da arte, os primeiros trabalhos dedicados a pensar a relação entre as imagens e o corpo feminino foram produzidos em consonância com a emergência, nos anos de 1970, de um movimento político nas artes que atualmente conhecemos por arte feminista - cujo termo, de fato, é tão difuso como pouco tangenciável ${ }^{2}$. Em 1971, Linda Nochlin (1988b, p. 146) denunciou, em seu célebre artigo Why have there been no great women artist?, como o campo da história da arte esteve marcado por um olhar masculino, branco e ocidental. Mais do que isso, a autora partiu dessa questão para problematizar a necessidade não apenas de pensar a questão das mulheres, mas de transformá-la em um catalisador, em um instrumento intelectual de cunho interdisciplinar capaz de apontar tensionamentos cruciais para o enfrentamento do sexismo que constituiu a própria arte e sua história.

Por essa perspectiva, a historiografia feminista da arte apontou para como o engendramento do fazer artístico concedeu ao corpo feminino um lugar tão recorrente quanto específico nos sistemas de artes, uma vez que esses sistemas atendiam às necessidades, aos desejos e às fantasias masculinas (Nochlin, 1988a). Para Linda Nochlin, o século XIX foi exemplar no processo de engendramento das imagens do corpo feminino, tendo em vista o lugar que os "mitos sexuais" ocuparam nesse período. As artes, para a autora, não se constituíram como uma espécie de "complô masculino", mas como um reflexo dos lugares sociais reservados aos sexos: "a imagem do homem é de poder, possessão e dominação, a da mulher de submissão, passividade e disponibilidade" (Nochlin, 1988b, p. 146) - dicotomia

2 Os anos 1970 observaram a emergência do conceito arte feminista - mas isso não sem tensionamentos. Afinal, e como pergunta Kathy Battista (2013, p. 1), "o que é uma obra de arte feminista?”. Segundo a autora, a prática artística feminista não pode ser compreendida nos mesmos sentidos de outros movimentos artísticos (como o expressionismo abstrato, o cubismo, o dadaísmo...), já que "não há um único estilo, meio de expressão ou aparência para as obras feministas". Desafiando as grandes classificações artísticas, a expressão arte feminista se refere muito mais a uma preocupação política de artistas com suas obras do que a um movimento temporalmente e esteticamente coeso, "levando-nos a questionar se o termo arte "influenciada pelo feminismo" não seria mais apropriado" (Battista, 2013, p. 1). Contudo, assim como Battista (2013, p. 1), escolhemos utilizar o termo arte feminista por uma questão de inscrição e alinhamento a um campo de pesquisa: os estudos feministas. 
atestada e reforçada pelo sistema acadêmico oitocentista. As imagens dos corpos femininos atendiam, nesse sentido, a demandas universalizantes sobre o feminino na modernidade, frequentemente colocando em cena o poder e a supremacia dos homens sobre as mulheres.

Dessa discussão mais ampla, destacamos um elemento decisivo: pode-se dizer que, acima de tudo, os regimes visuais demarcavam, retificavam, com maior vigor, o lócus ocupado pelas mulheres nos discursos sobre a diferença sexual: "feminino igual ao corpo, sexualidade igual ao corpo feminino", como interpretou Teresa de Lauretis (1984, p. 149-150). Em outras palavras, o século XIX foi palco da consolidação de uma austera cultura política de gênero, em que "cientistas e homens cultos da época [esforçavam-se] em entender a especificidade feminina ou, melhor dizendo, a natureza da mulher, para formular seus discursos a respeito das relações entre homens e mulheres, definindo seus lugares e estabelecendo seus papéis"(Martins, 2004, p. 36).

Ao objetivar as mulheres, grande parte da crítica indicava que os artistas - no masculino - produziam imagens marcadas por conotações específicas sobre o corpo e a natureza femininos: algo passivo, disponível, possuivel e impotente. Com a emergência da misoginia oitocentista, as práticas culturais, ao enfatizar a taxionomização da humanidade em dois sexos hierarquicamente desiguais, traziam à baila códigos de feminilidade correntes no período - o que, por consequência, demarcava qual era o papel dos homens nos jogos de poder travados com seu outro, as mulheres.

O homem está ausente das imagens, mas é seu discurso, sua visão, sua posição de dominação que dão significado às imagens. $\mathrm{O}$ artista individual não se expressa simplesmente, mas é, ao invés disso, o utilizador privilegiado da linguagem de sua cultura, que preexiste a ele como uma série de códigos reforçados historicamente, sinais e sentidos que ele manipula ou até transforma, mas nunca pode existir fora deles. (Parker e Pollock, 1981, p. 116)

Nesse fragmento do clássico livro de Rozsika Parker e Griselda Pollock, Old Mistresses: Women, Art, and Ideology, observamos como a objetivação das mulheres nada mais foi do que fruto das fantasias masculinas, um produto e uma prática instituidora de redes de força de gênero e de sexualidade. Para além dessas marcas, Griselda Pollock (2003, p. 135) demonstrou como, ainda, outros marcadores sociais (como o discurso racial, por exemplo) se entrelaçaram com o gênero, fazendo as representações dos corpos femininos, como as pinturas oitocentistas da rainha Cleópatra VII do Egito, um perigoso signo das ideologias de dominação masculinas ocidentais. Nessa perspectiva, e numa análise das imagens do corpo de Cleópatra considerando esses marcadores, tais pinturas estariam inextricavelmente atravessadas por vetores de uma lógica de dominação colonial e de gênero, cumprindo um papel político fundamental na manutenção dos discursos emergentes sobre as diferenças humanas no século XIX.

Se trazemos essas discussões aqui é porque nosso objetivo é mostrar, historicamente, as complexas relações que tramam imagem e formas específicas de produzir, a um só tempo, o corpo feminino e a diferença sexual pela arte — algo evi- 
denciado também por Loponte (2002). Sublinhamos que tais relações não apenas dão a ver como são constituídas as marcas de gênero e sexualidade, mas, igualmente, nosso olhar e nossas formas de analisar, até hoje, as imagens.

Assim, entendemos que a prática do "pênis como pincel", utilizando a metáfora de Carol Ducan (1977), não foi um sintoma exclusivo da austeridade dos discursos da diferença sexual oitocentista. Com a emergência das vanguardas artísticas na segunda metade do século XIX, o conceito de beleza e uma forma hegemônica de representar o corpo feminino que marcou a produção artística nas Academias de Belas-Artes foram sistematicamente abandonados, mas não desapareceram; ao contrário, assumiram uma nova forma de expressão (Steiner, 2002).

Carol Ducan (1977, p. 48) destacou como, nos movimentos das vanguardas, artistas como Munch, Klimt e Moreau mantiveram certa relação com uma concepção de beleza e de sexualidade em voga na pintura acadêmica, mas observou também, a partir do século XX, uma mudança radical: as representações do corpo feminino tornavam-se "bestiais, carnívoras e visualmente grotescas".

Em imagens de femininos monstruosos de Picasso, de Rouault, dos surrealistas e de Kooning, o medo das mulheres e as fantasias masculinas de inferioridade foram projetadas, objetivadas e universalizadas. [...]. As mulheres de Demoiselles d'Avignon, de Picasso, apesar de fisicamente mutiladas e nuas (vulneráveis), encaram agressivamente o espectador, são impenetravelmente mascaradas e dispostas com pontas afiadas, perigosos corpos-videntes. (Ducan, 1977, p. 48)

Femmes fatales. Avatar da modernidade, o corpo cubista das prostitutas de Picasso evidencia um paradoxo: o medo e o fascínio do corpo feminino. Para Anna Chave (1994), o paradoxo da pintura de Picasso permitiu à crítica feminista fraturar as normas de gênero das quais essa pintura é símbolo, uma vez que as senhoritas de Avignon não são simplesmente figuras impotentes dadas ao deleite masculino. Por meio disso, a historiadora pontuou como, particularmente nas últimas décadas, uma audiência masculina tem chamado a atenção para o caráter ameaçador e terrível dos traços dos corpos cubistas das prostitutas retratadas por Picasso - uma perturbação que pode, aliás, ser potente aos feminismos.

Para além da compreensão acerca da própria imagem e da multiplicação de seus sentidos, importa pensar como, de distintas formas, o corpo feminino acaba por constituir-se, em grande medida, como um paradigma da arte ocidental, tendo assumido, especialmente nos dois últimos séculos, um lugar fundamental para a manutenção de uma cultura política de gênero marcadamente androcêntrica. Lynda Nead (1990) chamou a atenção para a necessidade de pensar os corpos femininos na arte não somente como testemunhos da sexualidade masculina e feminina, mas também como frutos de toda uma indústria cultural. A autora refere-se a uma linguagem e, de modo mais amplo, às instituições que fundamentam e/ou criam definições particulares de gênero e sexualidade. Em suma, a história da chamada arte feminista demonstrou como a arte e a historiografia da arte instituem gênero e sexualidade, mas também destacou, por outra via, os modos como o gênero e a sexualidade estruturam, enquanto fenômenos culturais, o próprio campo artístico e sua história (Parker e Pollok, 1981). 
Com que fins, precisamente, trazemos estas considerações? Entendemos que gênero e sexualidade não são concebidos por estas autoras somente como categorias sociais da diferença humana, mas como uma espécie de doxa que opera simbolicamente em diferentes espaços do social. Ou seja, se o gênero e a sexualidade foram por muito tempo estudados como um dos efeitos da dominação e da normalização, fez-se necessário entender de que maneira eles são parte estruturante de instituições e formas de pensar (Martins, 2011).

Neste âmbito, é sabido o quanto os estudos feministas têm se debruçado sobre como o gênero opera como organizador do social, destacando como diversas instituições e práticas são constituídas e constituem o conceito. Inscreve-se, nesse pressuposto, uma articulação intrínseca do gênero com o campo educação, tendo em vista as complexas formas como os processos culturais veiculam saberes e valores, tornando-se partícipes dos processos de subjetivação dos indivíduos (Martins, 2011; Meyer, 2003; Scott, 2012). De fato, o campo da educação também vem se esforçando em questionar a íntima relação entre as imagens e a racionalidade masculina, assumindo, para isso e como ponto privilegiado de sua crítica, a tarefa de entender que as imagens, tal como propôs Guacira Louro (2008), exerceram e exercem pedagogias de gênero e sexualidade.

Dito isso, perguntamo-nos, de modo especial, sobre olugar das imagens nas pesquisas e análises que vêm orientando essas discussões no campo da educação. Para tanto, foi realizado um levantamento dos trabalhos apresentados no GT 23 - Gênero, Sexualidade e Educação, vinculado à Associação Nacional de Pós-Graduação e Pesquisa em Educação (ANPEd), desde sua criação, como Grupo de Estudos (GE), em 2003, até o $37^{\circ}$ Encontro da ANPEd, em 2015. A escolha pela imersão nesse expressivo conjunto de textos se deu, em um primeiro momento, pela centralidade da ANPEd no que diz respeito à visibilidade e à circulação, no âmbito nacional, de pesquisas sobre o campo da educação. Além disso, conforme já analisado por Márcia Ferreira, Georgina Nunes e Márcia Klumb (2013), percebe-se uma presença ainda muito rarefeita tanto de artigos vinculados ao campo da educação nas revistas feministas como, igualmente, de artigos sobre gênero e sexualidade nas revistas de educação. Assim sendo, delimitamos o levantamento à ANPEd por considerar, na esteira de Cláudia Maria Ribeiro e Constantina Xavier Filha (2015), o GT 23 um ponto de referência e de encontro de pesquisadoras e pesquisadores que, até o momento de criação do então GE, desenvolviam, muitas vezes de forma isolada, pesquisas e práticas pedagógicas voltadas para o tema do gênero e da sexualidade. Desse modo, o GE 23 - tornado GT em 2005 - se constituiu como um "espaço legitimado no interior da mais importante associação brasileira de educação, para constituir uma rede que ampliasse as possibilidades para as visibilidades e para o fortalecimento do campo, marcando uma consolidação acadêmica e política" (Ribeiro e Xavier Filha, 2015, p. 2).

Assim, metodologicamente, e considerando um universo de 164 trabalhos apresentados nos mais de 10 anos de história do GT 23, encontramos 12 comunicações que, em alguma medida, voltam suas análises para a cultura da imagem. Destas, apenas nove comunicações tomam efetivamente a imagem como material empírico, e, portanto, é esta última amostra que nos serve para o debate. Assim, se 
assumirmos, então, apenas os critérios de seleção dos textos, alguns dados já mereceriam a nossa atenção: pouco mais de 5\% dos trabalhos apresentados no GT tomam as imagens como elemento de análise central - o que talvez nos aponte uma demanda investigativa importante, considerando a prevalência das imagens hoje, em nosso cotidiano e nossos modos de existir. Além disso, apesar da pluralidade desses textos, as imagens foram estudadas, em grande medida, por meio de um amplo, mas semelhante, arcabouço teórico dos estudos feministas e dos estudos culturais em educação - neste caso, aqueles comprometidos com as proposições pós-estruturalistas. Se pudéssemos resumir as proposições investigativas em jogo, talvez fosse possível dizer que as autoras e os autores demonstraram, a partir de uma pluralidade de regimes de visualidade (filmes, novelas, jogos eletrônicos, propagandas, game shows), como as imagens, entendidas como artefatos culturais, operam como potentes pedagogias culturais na contemporaneidade, transmitindo saberes e valores, palavras e conselhos, que nos interpelam cotidianamente e, assim, ensinam modos normativos de ser e de viver gênero e sexualidade.

Também merece ser dito, a título de primeiras considerações analíticas sobre os trabalhos do GT 23, que, diferentemente das críticas da história da arte, o autor (no masculino) não vem se configurando como um dado relevante nos debates em educação (no caso da história da arte, as imagens eram, antes de tudo, frutos do desejo e do fascínio de um artista, não por acaso homem, e expressavam uma cultura masculinizada mais ampla) - o que, por certo, confere às análises ligadas ao campo da educação uma marca importante. Assim colocado, é possível afirmar que, de acordo com as perspectivas teóricas mais frequentemente assumidas, as imagens não se configuram, de modo isolado, como resultado dos desejos e das intenções de um sujeito individual, mas, antes, como efeitos de uma rede discursiva mais ampla que atravessa os sujeitos e as práticas.

A partir desse panorama geral dos trabalhos do GT 23, gostaríamos de problematizar - levando em consideração, de modo singular, a pluralidade teórico-metodológica e a constante autocrítica que têm acompanhado a produção do GT 23 e o próprio campo dos estudos feministas (Ribeiro e Xavier Filha, 2015) - o lugar que essas autoras e esses autores construíram para as imagens, perguntando, sobretudo, sobre as implicações teórico-metodológicas estabelecidas nessa relação. Tal empreendimento tem como intuito apontar algumas contribuições e, quem sabe, alguns desafios que essas perspectivas sobre as imagens nos impõem para a edificação de uma cultura filógina.

\section{A IMAGEM-SABER QUE NOS CONFORMA}

Ao iniciarmos um caminho analítico para pensar a relação entre imagem e os estudos de gênero em educação, é importante mencionar uma marca decisiva presente, direta ou indiretamente, nas produções do GT (e, por certo, do campo): a ideia de que, como propõe Guacira Louro (2008, p. 18), desde os anos 1990, não nascemos corpos de gênero e sexualidade, mas apreendemos, paulatinamente, ao longo da vida, a viver e estar dentro de uma norma de gênero e sexual. Com efeito, atentamos para o fato de que o campo da educação, no Brasil, distanciou-se de uma 
perspectiva de que gênero e sexualidade são algo que possuímos naturalmente, em direção à ideia de como, antes, a cultura nos sugere, anuncia e promove modos de fazer-se homens e mulheres, bem como possibilidades de experienciar o desejo sexual: "a inscrição dos gêneros - feminino ou masculino - nos corpos é feita, sempre, no contexto de uma cultura [...]. As possibilidades das sexualidades — das formas de expressar os desejos e os prazeres - também são sempre socialmente estabelecidas" (Louro, 2003, p. 11).

Deste ponto específico - de que fazemo-nos um gênero e uma sexualidade por meio uma complexa pedagogia -, é que gostaríamos de problematizar as análises realizadas em educação considerando um elemento central: a presença do que chamamos imagem-saber, que diz, nomeadamente, do trabalho, bastante disseminado entre as pesquisas do GT 23, de vincular as imagens a uma espécie de mistica feminina contemporânea. Para chegarmos à ideia de imagem-saber, tomamos os trabalhos da ANPEd considerando três movimentos interrogativos: qual conceito de corpo esses trabalhos dão a ver? A que esse corpo nos convoca em termos de produção de sujeito? Que formas de resistência são possíveis diante das imagens desses corpos?

Ao pensar o conjunto de textos apresentados na ANPEd, é possível identificar um esforço conjunto em questionar o lugar dos corpos em uma certa economia política de gênero e sexual. Nesse movimento, uma pergunta parece persistir: de que corpo os textos da ANPEd falam? Falam do corpo da criança enredado pelo amor romântico na tela do cinema (Pereira, 2010); do corpo hipersexualizado de personagens como Minnie (Schwengber, 2013); dos corpos de Barbie (Roveri, 2007) e de Lara Croft (Mendes, 2005) em propagandas e videogames; do corpo da adolescente que agrada, entre o recato e a erotização, o olhar masculino em reality shows (Soares, 2006); do corpo masculino, viril e malandro, exaltado em novelas (Ribeiro e Siqueira, 2005); do corpo abjeto que se assujeita à norma em desenhos da Disney (Sabat, 2004); falam de um corpo inseparável da imagem que lhes conforma.

Mais precisamente, e prioritariamente sob o conceito de pedagogias de gênero e sexualidade, como já mencionado, os textos questionam as imagens dos corpos no espaço em que se fazem dotados de valores emblemáticos de nossa cultura, exprimindo e comunicando sentidos particulares de gênero e sexualidade. Por meio dessa compreensão, um conjunto variado de imagens foi trazido como parte do sistema de representação do corpo feminino de nosso tempo: campanhas publicitárias "sintomáticas de nossa cultura" (Schwengber, 2013, p. 4); videogames que humanizam a personagem principal por meio de "ligações culturais e sociais [...] impressas no sujeito [a personagem] e em seu corpo" (Mendes, 2005, p. 3); desenhos infantis que se constituem como "reprodução de códigos sociais, valores, hábitos e comportamentos socialmente aceitos" (Sabat, 2004, p. 1); imagens televisivas de um reality show concebidas como "via de acesso' a um tipo de juventude" (Soares, 2006, p. 1). Em suma, as imagens apresentadas nas comunicações em questão instituem um conjunto de saberes voltados para a docilização dos corpos e atuam, decisivamente, como uma espécie de arcabouço contemporâneo de saberes.

Assumindo esta particularidade como vetor de debate, a imagem-saber seria uma forma de tornar presente um tipo de saber - o que implica, nas mesmas análises, considerar suas relações constitutivas com as relações de poder. A imagem-saber 
seria, então, parte da mecânica do poder ou, mais especificamente, e retomando o conceito usado no início deste texto, da mecânica do que Betty Friedan chamou de mística feminina, atualizando-a e, portanto, mostrando como hoje ela ainda se faz decisiva. Ou seja, o que esses trabalhos indicam é que parece persistir uma mística feminina e, ainda, que ela opera de distintas formas: na produção do corpo perfeito de Barbie, pois a boneca "impõe uma significação corporal construída sob os moldes higienistas e eugênicos" (Roveri, 2007, p. 4); no corpo sedutor de meninas-adolescentes, "carregado de sexualidade" e em como "são convocadas ao prazer por meio do desejo e da fantasia dos garotos" (Soares, 2006, p. 7); no corpo da personagem Lara Croft, criado para ser possuído pelo olhar masculino e ser modelo para o olhar feminino (Mendes, 2005); do corpo de Minnie, que teve seus traços infantis transformados em uma imagem reveladora da "disponibilidade corporal feminina de Minnie e da objetivação do corpo enquanto objeto de desejo sexual" (Schwengber, 2013, p. 6).

Como se observa, a mística feminina assume aqui outras e novas configurações. Certamente, ela não atua mais pelo arquétipo da modern woman querelado por Betty Friedan, mas dissemina, ensina, com uma nova roupagem, códigos de gênero e sexualidade hegemônicos na contemporaneidade; códigos aos quais nossos corpos precisam se conformar e a partir deles se constituir. A imagem-saber dá a ver, assim, o corpo educado ou, bem mais do que isso, ela sugere toda uma rede de saber-poder contemporânea que visa à educação de indivíduos, constituindo-os em sujeitos de um corpo generificado e sexuado.

Com efeito, a imagem-saber seria algo semelhante ao que Foucault (1988, p. 109) denominou de focos locais de saber-poder, na medida em que "veiculam formas de sujeição e esquemas de conhecimentos". Sendo assim, podemos dizer que as estudiosas e os estudiosos em educação - mas também em história da arte, como vimos - assumem como tarefa fundamental questionar o lugar dos corpos em certa economia política que sustenta certos modos de viver gênero e sexualidade como verdades hegemônicas sob as quais devemos nos fazer sujeitos. Os textos defendem, em alguma medida, que o corpo esteve e está, diante dos diferentes suportes imagéticos estudados, mergulhado em um campo político. Nos textos do GT 23, a mística contemporânea se traduz, portanto, sob o signo desse investimento político sobre os corpos, em que as imagens são percebidas, trabalhadas, analisadas como um dos modos pelos quais as normas de gênero e sexuais nos constituem e pelos quais nos constituímos como sujeitos. Construídas como um instrumento da norma, as imagens transformam-se, nas comunicações ora analisadas, num elemento decisivo de uma tecnologia política do corpo.

Nas análises empreendidas no GT 23, compreende-se como esses focos locais de saber-poder, visíveis pelas imagens, nos produzem como sujeitos de um corpo generificado e sexuado que em muito se aproxima do pressuposto desenvolvido por Judith Butler (2004) a partir de Foucault: o corpo, a um só tempo, como ocasião e como condição do poder. No primeiro sentido - corpo como ocasião do poder -, Maria Schwengber (2013,p. 1) demonstrou, por exemplo, como as imagens promovem a "produção de corpos generificados", marcando as práticas imagéticas como parte de uma "maquinaria pedagógica" que "capta" os corpos em sua materialidade 
de forma "sutil" e "envolvente". O corpo como ocasião do poder seria, portanto, um resultado da inscrição do poder, isto é, o poder produz o corpo no ato mesmo em que age sobre ele.

No segundo sentido - corpo como condição do poder -, percebemos que as imagens, a exemplo de Barbie, são produzidas para "seduzir" as meninas, ensinando-as a necessidade de "se apoderarem desse corpo de plástico e desejá-lo para si mesmas" (Roveri, 2007, p. 7), ou seja, as redes de saber-poder investidas na imagem são, também, interdependentes da própria experiência dos indivíduos, convocando-os a uma relação de força consigo mesmos e com outrem para, assim, construírem seus corpos no ato mesmo em que tecem tais relações. $\mathrm{O}$ corpo como condição do poder é, portanto, o lugar de onde o poder também emana, de onde ele emerge.

Em suma, a imagem-saber se organiza por meio de um movimento que faz do gênero e da sexualidade fenômenos socioculturais que constituem a (ocasião) e são constituidos a partir da (condição) materialidade dos corpos. No entanto, interessa-nos, como já mencionado, propor, a partir disso, uma outra questão: a que essa imagem-saber nos convoca e, mais propriamente, a que tipo de sujeito ela dá lugar?

Os movimentos analíticos dos textos, ao inscreverem as imagens sob a égide do que chamamos de imagem-saber, dizem respeito a uma questão particular da relação do sujeito com a verdade. Dizendo de outro modo, e como desdobramento do conceito de imagem recorrente nesse panorama da produção acadêmica do GT, os trabalhos da ANPEd se lançam, quase que uníssonos, em pensar as imagens como pedagogias culturais e, sobretudo, como, nessa condição, participam ativamente no processo de sujeição dos indivíduos às normas de gênero e sexualidade hegemônicas.

Ao retomarmos as discussões desses trabalhos de modo a tornar mais claro como um conceito particular de imagem se articula a um tipo de relação do sujeito com a verdade, observamos algumas singularidades: Wânia Fernandes e Vera Helena Siqueira (2006, p. 7) apresentaram, na Reunião da ANPEd de 2006, o papel cultural do cinema como aquele de "disciplinarização histórico-social sobre os corpos". Em entrevistas com mulheres entre 60 e 80 anos de idade sobre suas experiências de juventude com filmes, as autoras constataram que o cinema "serviu como elemento estruturante para a (re)construção, (re)produção e circulação de regimes de verdades na construção da identidade de gênero dessas mulheres". Com efeito, o cinema se configurou, na análise das autoras, como uma "instância pedagogizante, contribuindo para a perpetuação de estereótipos sociais relativos aos comportamentos femininos/masculinos, divulgando modelos e naturalizando diferenças" (Fernandes e Siqueira, 2006, p. 15).

De modo semelhante, Ruth Sabat (2004, p. 1) demonstrou, em trabalho apresentado em 2004, como os filmes infantis reafirmam a "heterossexualidade como a sexualidade normativa"; ali, as imagens seriam parte de uma "economia de saberes" (Sabat, 2004, p. 9) em nossa sociedade, organizando a norma heterossexual por meio de sentidos que encontram eco em diferentes grupos sociais. Outro exemplo pode ser visto pelo trabalho de Fernanda Roveri (2007), centrado no estudo sobre a Barbie. Ali, entende-se que toda a estrutura imagética que envolve a Barbie convida as meninas a "consumir[em] os signos de gênero e sexualidade apresentados 
pela boneca, que vertiginosamente ensina e produz certas formas de pensar, de agir, de estar e se relacionar com o mundo" (Roveri, 2007, p. 4). Nessa mesma direção, Rosângela Soares (2006) demonstrou, na análise de programa de TV para jovens, como "o programa Fica Comigo parece estar ajudando a instituir um tipo de jovem cuja sexualidade é central; assim, torna-se possível afirmar que há uma pedagogia amorosa/sexual exercida sobre a juventude por esse programa" (Soares, 2006, p. 2). Em suma, o que demarcamos, nesses trabalhos, é o afastamento de uma noção linear entre a imagem e seus efeitos; ou, o que seria equivalente, o afastamento de uma noção de influência (ou seja, como se as imagens, em si, pudessem isoladamente produzir sujeitos desta ou daquela forma), porém em prol de outra noção, que indica a participação decisiva das imagens (em sua condição de sintomas de um tempo, ou de uma espécie de arcabouço de verdades contemporâneas, como vimos) nos regimes discursivos que buscam, antes de tudo, educar os sujeitos dentro de certas concepções hegemônicas de como viver o gênero e a sexualidade, concebidas e construídas, em nossa cultura, como verdades universais e já naturalizadas.

Assim, nos trabalhos analisados, percebe-se, que, frequentemente, o lugar de resistência é marcado por algo outro, que não a imagem (em outras palavras, a imagem não é tomada, ela mesma, como forma de resistência). É, pois, antes, um sujeito que vem a ocupar este lugar - geralmente, a professora ou o professor: "as imagens teriam que entrar no planejamento do/a professor/a como forma de experiência dialógica" (Schwengber, 2013, p. 11); pois os/as "educadores/as estabelecem uma relação mais crítica com as representações veiculadas pelo discurso cinematográfico"(Fernandes e Siqueira, 2006, p. 15). Em outras palavras, as imagens "não são artefatos a serem banidos [de nosso] cotidiano" (Sabat, 2004, p. 10), mas algo a ser incorporado ao cotidiano escolar, como elemento de crítica da cultura na qual estamos inseridos.

O fato de a capacidade de resistência se encontrar situada no exterior da imagem implica a presunção de um sujeito cognoscente, capaz de se apropriar, se assenhorar, da verdade das imagens - isso ao submetê-las a um olhar crítico para delas extrair, mediante as marcas históricas e culturais que supõe conhecer e combinar, o que elas sugerem, postulam, fazem circular. As professoras e os professores são, portanto, de algum modo, convocadas e convocados a utilizar os diferentes produtos imagéticos em sala de aula, visando, sobretudo, a ocupar um lugar de mediadoras e mediadores capazes de intervir criticamente diante dessa espécie de mística, transformando a relação que os indivíduos estabelecem com as imagens.

Assim colocado, se pudéssemos, a partir das proposições aqui realizadas, resumir as contribuições pulsantes nos textos da ANPEd - e da história da arte feminista - aos estudos feministas, poderíamos pensar nas formas como esses trabalhos movimentaram uma crítica aos modos de subjetivação de gênero e sexualidade dos corpos. Observa-se como ali se efetiva, ainda que nem sempre diretamente, uma aposta também teórica sobre o próprio conceito de imagem, qual seja: tomar a imagem como enunciadora das verdades de nosso tempo, evidenciando, por meio disto, a falácia dessas verdades, a ficcionalidade de sua imutabilidade. Em outras palavras, os estudos da ANPEd assumem, em muitos sentidos, um importante lugar na luta contra o poder, expondo-o lá onde ele mostra sua violência, combatendo-o no es- 
paço mesmo em que ele foi historicamente inventado, no terreno sobre o qual ele se produz e - por isso mesmo - se revela ficção.

Contudo, e a partir das conclusões suscitadas pela leitura desses textos, podemos perguntar, afinal: que outras formas possíveis de análise de imagens seria possível ainda criarmos, para além destas, mais recorrentes, que privilegiam a tarefa de fazer com que as relações de poder-saber sejam efetivamente visíveis; de fazer com que possam aparecer, ferindo-as lá onde se mostram tão sedutoras e, por isso, mais ardilosas na produção de corpos e sujeitos de um determinado tipo?

A pergunta, por certo, não é nova. Aliás, no campo dos estudos de gênero e educação, e das mais diferentes formas, algumas autoras têm argumentado em favor de um outro caminho possível para pensar as imagens para além da ideia de sua participação na manutenção de uma mística feminina. Patrícia Balestrin e Rosângela Soares (2012, p. 95) nos provocam, por exemplo, por meio do campo da antropologia visual, a "pensar (sobre) outros modos de viver, de estar, de se fazer sujeito de uma cultura, pensar (sobre) outras formas de conhecer e mesmo outras formas de pensar". Por meio de uma etnografia da tela, as autoras tensionaram a imagem cinematográfica como um texto que podemos, em um exercício antropológico visual, ler. Essa leitura, por um lado, pode estar radicada na caracterização, mais uma vez, das formas hegemônicas de constituição da imagem e, com efeito, dos sujeitos - como é o caso, para as autoras, do filme brasileiro O Céu de Suelly, sobretudo no tocante aos códigos de maternagem que o filme ensina e em seu viés "moralista" (Balestrin e Soares, 2012, p. 106); mas, por outro lado, as autoras, ainda que de forma apenas anunciativa, apontam que as imagens também podem nos convidar a deslocarmos nosso olhar e ver outros ângulos e perspectivas. Neste caso, para elas, o mesmo filme poderia dar a ver outras possibilidades de entender o gênero pela imagem, indicando um alargamento dos modos de ser mulher por meio de outras contingências e desafios (Balestrin e Soares, 2012, p. 106) - para além, portanto, de seu caráter normalizador.

Somado a isso, Cláudia Ribeiro e Constantina Xavier Filha (2015, p. 17) convidam-nos a um importante desafio no que se refere às discussões propostas no GT 23: "a de pensarmos se o conceito de gênero não traz à discussão a desconstrução do binarismo do masculino e feminino de forma relacional" - algo que, para as autoras, poderia ser problematizado a partir de discussões teóricas ainda incipientes no GT, tais como aquelas favorecidas pelo pensamento de Judith Butler e pelos estudos queer. Para isso, as autoras lançam questões centrais a nós: "Como repensar conceitualmente gênero? Ressignificá-lo? Construí-lo e desconstruí-lo em nossos estudos?" (Ribeiro e Xavier Filha, 2015, p. 17).

Instigados por essas proposições e pelos resultados da análise dos materiais, enfatizamos a importância teórico-metodológica de pensarmos além da imagem como veiculadora das verdades hegemônicas (além, portanto, de uma imagem-saber) e do quanto esse elemento poderia nos sugerir uma possível ressignificação do gênero. Talvez, como efeito dessa proposta, seja possível pensar a imagem no interior de nossas investigações também como sendo, ela mesma, possibilidade de resistência. Nesse sentido, então, haveria um importante deslocamento conceitual a ser enfatizado e empreendido: não mais — ou não apenas — tendo o sujeito como elemento 
facilitador, por meio da crítica, das formas de resistência, mas tomando a imagem como situada nas margens de novas possibilidades de pensamento e de criação. E é sobre esses elementos que trataremos a seguir.

\section{IMAGENS-FALENAS: BALIZAS PARA OUTRO CAMINHO INVESTIGATIVO}

Se cremos ser importante apontar para outras relações possíveis a serem estabelecidas com as imagens, torna-se fundamental indicar os deslocamentos incluídos nessa aposta. Para isso, gostaríamos de mostrar os efeitos teóricos implicados numa concepção de imagem-saber e no que ela se sustenta, nos termos de uma filosofia da imagem. Neste caso, e com base nas discussões realizadas acerca dos trabalhos analisados, isso implicaria perguntar como, ao valer-se de uma imagem como sinônimo de saber, essas discussões acabam, em alguma medida, por inventar o próprio objeto que buscam desconstruir.

De algum modo, pode-se dizer que o que sustenta o conceito de imagem-saber está radicado em certa hegemonia do visivel - entendido aqui como volume primeiro de algo que se coloca diante de nosso olhar; como materialidade pura, sob a qual nosso olhar se choca no instante de contato com a imagem (Didi-Huberman, 2010). Assim considerado, o visível inscreve-se no tangível, tornando o próprio ato de ver correspondente a uma experiência tátil com a imagem. $\mathrm{O}$ visível, nesta discussão, permite-nos acesso ao volume primeiro das imagens, consola nosso olhar, confortando-nos sob um sentimento de efetivamente algo saber, de súbito, sobre aquilo que vemos.

Qual o lugar que o visível assume na história do olhar, sobretudo o olhar que direcionamos às imagens sobre corpos? A categoria do visível se desdobrou, na história da arte e em outras áreas de estudos da imagem, como uma exigência teórica de tom universalizante, convocando-nos a discernir e a reconhecer o que está ali, na imagem, dado a ver. Ou seja, a hegemonia do visível pressupõe, como consequência, um saber sobre as imagens: um saber conquistado pelo que se verifica e se reconhece diante de nossos olhos.

Esse tipo particular de experiência para com a imagem não é novo. Ao contrário, o visível encontra suas condições de possibilidade desde o Renascimento, sustentado pela produção da imagem como mimese. A partir disso, o visível se tornou, pouco a pouco, um marcador decisivo ao estruturar (e ser estruturado) por metodologias das mais diversas, como a iconologia e a semiologia, que têm grandes reverberações nas análises contemporâneas de imagem. A exemplo da iconologia de Erwin Panofsky, Georges Didi-Huberman (2013, p. 135) nos mostra como o movimento crítico panofiskiano, na história da arte, esteve implicado com uma vontade de compreender a significação particular das imagens, situada na possibilidade de "toda a forma visível já [trazer] o 'conteúdo conceitual' de um objeto ou de um acontecimento; todo objeto, todo fenômeno visível já [trazer] sua consequência interpretativa”. Em outras palavras, existiria, nessa forma de compreender a imagem, uma intersecção entre o ato de ver e o ato de saber, em um movimento 
que busca desvelar pelo olhar - não qualquer olhar, mas o olhar de um clínico, um olhar-que-sabe do sujeito cognoscente - o sentido mesmo que existiria nas imagens. A análise das imagens repousaria, portanto, no visivel e, com efeito, no que se pode saber por meio dela; enfim, nos termos de nossa discussão, falaríamos de uma imagem-saber.

Inspirados em Georges Didi-Huberman, entendemos que a imagem-saber que se faz presente nos textos que debatemos anteriormente é sintomática de uma exigência de descrever o que reconhecemos na imagem, sua verossimilhança com o presente. A imagem se torna e é tomada, consequentemente, como superfície plenamente visível. No entanto, o perigo pulsante dessa concepção reside, justamente, no momento em que a imagem é submetida à vontade de saber daquelas e daqueles que dela se ocupam para efetuar suas análises; no momento em que estas e estes criam um objeto específico sob a presença do visível, qual seja, as imagens como instrumentos inarredáveis de uma espécie de mistica feminina contemporânea.

Os últimos trabalhos de Judith Butler podem, talvez, nos dar algumas pistas para compreendermos a relação que estabelecemos entre saber e imagem no campo do feminismo. Nos termos de Judith Butler (2009), o nosso olhar é organizado por marcos $(\text { frames })^{3}$ que nos permitem reconhecer as formas hegemônicas de viver o gênero e a sexualidade. Mas, ao mesmo tempo, os marcos (frames) também acabam por reduzir o visível a elas: "os marcos (frames) não exibem simplesmente a realidade, mas participam ativamente de uma estratégia de contenção, produzindo e aplicando o que irá contar como realidade"(Butler, 2009, p. 12, grifos nossos). Nessa perspectiva, eles instrumentalizam certas versões de realidade, "sempre jogando algo fora, sempre mantendo algo fora, sempre desrealizando e deslegitimando versões alternativas da realidade [...]" (Butler, 2009, p. 12). Mais precisamente, os marcos (frames) educam o nosso olhar por meio de categorias, convenções e normas, dando-nos as condições ontológicas de, antemão, saber reconhecer e, mais do que isso, nomear o que vemos. Em outras palavras, o nosso olhar é marcado (framed) pelas verdades existentes de nosso tempo, por certas versões da realidade estabelecidas - inclusive academicamente - pelas normas de gênero e sexualidade e do que, a partir delas, é desejável discutir, problematizar.

No caso dos estudos feministas, o discurso normativo de gênero e sexualidade é reconhecível, legível, discernível, na visibilidade das imagens, uma vez que nosso olhar está marcado ( framed) pelas próprias normas que procuramos problematizar na mística feminina. Nesse prisma, as imagens são, sob nossa vontade de saber, frequentemente construídas, e mesmo selecionadas em nossas pesquisas, a partir de um ideal normativo que permite com que reconheçamos, em sua dimensão visível, algo que corresponde àquilo que as normas nos permitem nomear. Em suma, as

3 Para os distintos usos de frame, a autora se vale do sentido polissêmico que o termo possui em inglês com o intuito de pensar nas várias formas como os frames funcionam na organização dos modos de se fazer sujeito em nossa cultura. Com efeito, uma vez que não temos tradução literal do termo em português, tentamos respeitar a abordagem de Judith Butler, trazendo sempre uma tradução possivel do termo e, por isso, acompanhada da palavra original. 
imagens só são visiveis, legiveis, pois as próprias normas nos permitem reconhecer, ler e nomear aquilo que vemos em seu volume primeiro — neste caso, os pressupostos da mística.

A crítica feminista constrói um ideal sobre as imagens (sua capacidade de fazer ver a mística), mas, ao fazer isso, arrisca-se a sujeitar o seu objeto (a imagem) a esse ideal. Nos termos de Didi-Huberman (2013, p. 115-116), na história da arte, sujeitar a imagem a um ideal correspondeu a fazer dela um objeto, "imaginando-o, vendo-o ou prevendo-o - em suma, dando-lhe forma e inventando-o por antecipação"; isso corresponde a situar-se "diante dos poderes de invenção de um discurso sobre o objeto que ele pretende descrever" (Didi-Huberman, 2013, p. 115-116, grifos nossos).

Deriva dessa questão conceitual um pressuposto importante: permanecer no nível do visível, na ordem do olhar emoldurado (framed) pelas normas, é assumir um ato inarredável de exclusão daquilo que, nas imagens, nos escapa, daquilo que nelas não se faz visivel, não se faz, justamente, saber. Ora, pautar-se na reconhecibilidade, no visível, não denuncia apenas como as imagens são frutos de uma vontade de saber, educando-nos a um tipo de conformação aos modos de viver o gênero e a sexualidade, mas, ao mesmo tempo, constrói as próprias imagens por uma vontade de saber outra - neste caso, relativa aos enfrentamentos travados pelos estudos feministas contra a lógica hegemônica de viver os corpos. Ou seja, num movimento circular, é pela norma que deduzimos um saber sobre as imagens, mas fazemos da própria crítica da norma - a partir das imagens, por causa das imagens — algo irremediavelmente edificado mediante a ordem do discurso que a crítica busca romper.

E haveria como suscitarmos um outro olhar sobre as imagens? Acreditamos que sim e destacamos, por exemplo, como artistas ligadas à segunda onda feminista de 1960-1970 reivindicaram o valor do sentido erótico do corpo feminino para as próprias mulheres, desafiando a lógica de um corpo dado ao olhar e ao deleite masculino. Para a historiadora da arte Anna Chave (2010), houve, nesse período, uma preocupação das artistas de que suas obras fossem reutilizadas para agendas masculinas mais conservadoras, na contramão, portanto, dos objetivos políticos de suas propostas artísticas. Diante desse risco (de ter a imagem apropriada por e situada em outro regime de sentido), artistas como Barbara Hammer ou Laura Cottingham, buscaram expor seus trabalhos em canais subculturais acessíveis unicamente a uma audiência feminina. Outras artistas, como Catherine McKinnon e Andrea Dworkin, produziram uma arte com uma postura antipornô, com o objetivo de questionar o caráter sexista das imagens que fazem do corpo feminino um objeto para o olhar e o prazer masculinos; já artistas como Deborah Bright e Annie Spinkle reivindicaram um pornô positivo, construindo filmes como instrumento do ativismo feminista, isto é, da reivindicação do corpo e do prazer para as próprias mulheres.

Em uma chave de leitura butleriana, poderíamos pensar que as relações aqui brevemente descritas entre artistas e arte foram, em algum sentido, mediadas, orquestradas, pelas formas como nossas visões de mundo, nossos modos de ver, são marcados (framed) pelas normas de gênero e sexualidade. Ou seja, foi na luta travada com essas formas de enquadramento (frames) que emergem na espessura do visível que as artistas produziram suas obras. Nelas, e a partir delas, um outro espaço de visibilidade se constituiu — justamente aquele que não se dá a ver de imediato. Neste caso, pode-se dizer que as artistas operaram sobre as imagens hege- 
mônicas sobres os corpos femininos não para delas produzir um saber. Antes disso, até mesmo porque inscritas em um campo distinto - a arte - elas operam ali mesmo, nos vazios, nas frestas que também as imagens a princípio normalizadoras (como as imagens pornôs) possuem, agutizando-os.

O que vemos, portanto, é aquilo que Didi-Huberman já pontuava, ou seja, que há uma alternativa aos modos conformados de ver, aos modos que antecipam (e por isso, muitas vezes, acabam por produzir) os sentidos das imagens - e que, por certo, poderiam ser tomados por nós, em nossas investigações, inclusive sugerindo formas de ressignificação do gênero, como proposto pelas discussões de Ribeiro e Xavier Filha (2015), já mencionadas. Essa alternativa

[...] se baseia na hipótese geral de que as imagens não devem sua eficácia apenas à transmissão de saberes - visíveis, legíveis ou invisíveis - , mas que sua eficácia, ao contrário, atua constantemente nos entrelaçamentos ou mesmo no imbróglio de saberes transmitidos e deslocados, de não-saberes produzidos e transformados. (Didi-Huberman, 2013, p. 25)

Para isso, no entanto, somos convocados, como pesquisadoras e pesquisadores, a um outro movimento de olhar (e, ainda, quem sabe, a um outro movimento de selecionar as imagens em nossas pesquisas): "um olhar que não se aproximaria apenas para discernir e reconhecer, para nomear a qualquer preço o que se percebe". Antes disso, trata-se de um olhar que, "primeiro, se afastaria um pouco e se absteria de clarificar tudo de imediato. Algo como uma atenção flutuante, uma longa suspensão do momento de concluir [...]" (Didi-Huberman, 2013, p. 25).

Se a imagem não precisa ater-se à dimensão do saber, como se daria, então, sua análise? Se, ao mesmo tempo, nossos modos de olhar para ela não mais se voltam para a perspectiva de clarificar e descrever os sentidos que ali se tecem, como se daria a construção do que sobre ela podemos dizer? Mais uma vez, é Didi-Huberman quem nos oferece uma potente metáfora para pensarmos sobre o conceito de imagem, qual seja, o da imagem-falena (em alusão à espécie de borboletas noturnas). Pensar na imagem como falena implicaria apostar, de início, em sua dinâmica de movimento e, ainda, de efemeridade: é na abertura e fechamento contínuos das asas de uma falena que nos defrontamos menos com suas formas exatas e definíveis e mais com sua leveza e movimento. Podemos, assim, junto ao autor, assumir que os sentidos da imagem se dariam justamente neste espaço que não nos é reconhecível de imediato, mas que emerge como fugacidade:

Se realmente quisermos ver as asas de uma falena, primeiro, temos que matá-la e, depois, conservá-la em uma vitrine. Uma vez morta, e somente então, podemos contemplá-la tranquilamente. No entanto, se quisermos conservá-la viva - o que, no fundo, seria muito mais interessante -, somente veremos as asas fugazmente, por pouco tempo, num piscar de olhos. Isto é a imagem. A imagem é uma falena. Uma imagem é algo que vive e que só nos mostra sua capacidade de verdade numa cintilação. (Didi-Huberman, 2007, p. 19) 
Por extensão, entendemos que um gesto de análise implicado em nos assenhorearmos da imagem pelo saber, pelo visível que podemos ler por meio dos marcos (frames) da reconhecibilidade, só é possível mediante a morte das imagens. A imagem morre sob nossos alfinetes, suas cores esmaecem sob nossa lupa analítica e sua potencialidade, nesse momento de aparição da imagem, fugaz como o voo da falena, se perde sob nossa vontade de saber, deixando-nos no âmbito do visível.

Nas duas formas de abordar a imagem (a que mata a falena ou a que a conserva viva), relações de força sobre ela se impõem: de um lado, aquelas que, por se organizarem em torno de um saber sobre a imagem, apelam àquilo que ela tem de normatizador - o que implica, como vimos, conceber a resistência como algo que não está ali, na imagem, mas concentrado, por exemplo, no sujeito que a olha. De outro lado, no entanto, as relações de força podem se dar na imagem, ou seja, ela mesma pode ser tomada como palco de disputas de forças, possibilitando não apenas a sugestão da pedagogia normatizadora, mas a emergência de espaços vazios, de frestas de sentido e da potência que reside no não saber. Neste caso, então, a resistência não se localiza prioritariamente fora da imagem, mas, antes, a constitui como tal; em outras palavras, a imagem pode ser, ela mesma, resistência.

Apostar nas relações de força que se exercem na imagem significa também apostar que a resistência emerge do risco do não reconhecimento - algo que exige outra forma de enfrentar os modos como os discursos sobre gênero e sexualidade se exercem sobre os corpos que não se conformam às verdades existentes. Significa, assim, sustentar que as imagens carregam uma potência de romper com o que marca (frame) um contexto, possibilitando, por exemplo, a criação por seu caráter de aparição em outros contextos (como vimos nas imagens das artistas mencionadas). Ao exceder os marcos (frames), as imagens possibilitam, no próprio ato de constituir outros marcos possíveis, certo afrouxamento dos mecanismos de controle, em um constante desfazer das normas. Diante da imagem como falena sugerida por Didi-Huberman (2007, p. 19), um outro modo de abordagem, então, se impõe: a de se deixar conduzir pelo que não se vê e, portanto, não se sabe.

\section{CONSIDERAÇÕES FINAIS}

Ao tomar como centro do debate algumas proposições da historiografia da arte feminista e, mais especialmente, os trabalhos apresentados no GT 23 da ANPEd, buscamos indicar alguns percursos pelos quais os estudos feministas têm estabelecido uma relação crítica com as imagens, tendo como foco a crença em sua ativa participação na manutenção e revitalização de uma espécie de mística feminina contemporânea. Para tanto, assumimos como fundamento da discussão a análise dos textos apresentados no GT que tinham a imagem como vetor central de debate, indicando, a partir disso, o modo como, em seu conjunto, eles acabam por movimentar algumas discussões singulares em torno daquilo que nomeamos de uma imagem-saber. Podemos dizer que, ao sustentar a ideia de imagem-saber, os trabalhos do GT 23 vêm realizando três apostas teórico-metodológicas: 
1. a inscrição da imagem sob a ordem do saber, dando a ver um conceito de imagem que, como fruto da mística, produz os corpos a partir das normas de gênero e sexualidade;

2. a ideia de que os sentidos da imagem-saber colocam em jogo uma relação específica dos indivíduos com as verdades de nosso tempo, sistematizando, a partir disso, que as imagens são práticas educativas normatizadoras sob as quais e pelas quais nos constituímos como sujeitos das verdades hegemônicas de gênero e sexualidade;

3. a ênfase numa relação assujeitadora com as verdades pulsantes na imagem-saber, tendo como resultado o pressuposto de que as formas de resistência possíveis não se efetivariam na imagem, mas fora dela.

Tais considerações nos levaram ao cerne das discussões de Georges Didi-Huberman: aquela que nos mostra o desejo de permanecermos no volume primeiro da imagem, em sua dimensão visível e, com isso, nos permitindo tecer, com a imagem, uma relação intermediada pela ordem do saber. Na articulação com as problemáticas lançadas por nossa discussão, entendemos, com Judith Butler, que tal ordem do saber se vincula a certos marcos (frames) normativos de gênero e sexualidade, que demarcam (frame) os modos como olhamos o visível da imagem. É por meio dos marcos (frames) de gênero e sexualidade que podemos, de antemão, reconhecer e nomear o que pulsa no volume primeiro da imagem.

No entanto, ao sermos convidados por outras autoras também vinculadas ao GT 23 (Balestrin e Soares, 2012; Ribeiro e Xavier Filha, 2015) a pensar em outras relações possíveis com as imagens, sugerirmos, a partir da metáfora da falena de Didi-Huberman, o investimento na potência das imagens de nos convocar a outras escolhas teórico-metodológicas. Com efeito, diante das imagens, estaríamos na presença da possibilidade de nos desfazermos de nossa vontade de saber. Se, como afirma Foucault (2014, p. 252), entendemos que "devemos não somente nos defender [das relações de poder], mas também nos afirmar [...] como força criadora”, a metáfora da falena nos permite pensar que a resistência não emerge exclusivamente como descrição das relações de saber-poder, mas, igualmente, como possibilidade de invenção, de criação e de transformação de nós mesmos. Ou seja, as imagens, em nossas pesquisas, e dependendo do modo como as escolhemos para compor nossas problemáticas, poderiam nos permitir experienciar outras formas de resistência, provocando-nos, pelo não saber, a nos reinscrevermos diferentemente nos regimes de verdade dos quais somos sujeitos - por exemplo, em um processo de transformação do pensamento que torne as normas de gênero e sexual mais diluídas e porosas.

\section{REFERÊNCIAS}

Balestrin, P; Soares, R. "Etnografia de tela": uma aposta metodológica. In: Meyer, D; Paraíso, M. (Orgs.). Metodologias de pesquisa pós-críticas em educação. Belo Horizonte: Mazza Edições, 2012. p. 87-109.

Batтista, K. Renegotiating the body: feminist art in 1970s London. London: I. B. Tauris, 2013. 
Butler, J. Bodies and power revisited. In: Taylor, D; Vintges, K. (Eds.). Feminism and the final Foucault. Chicago: University of Illinois Press, 2004. p. 183-194.

. Frames of war: when is life grievable? New York; London: Verso, 2009.

Chave, A. New encounters with Les Demoiselles d'Avignon: gender, race, and the origins of Cubism. The Art Bulletin, New York: CAA, v. 76, n. 4, p. 596-61, Dec. 1994. Disponivel em: <https://goo.gl/WT6v9E >. Acesso em: 25 jun. 2016.

."Is this good for vulva?": female genitalia in contemporary art. In: NoLAN, D; Naumann, F. (Eds.). The visible vagina. New York: Francis Naumann Gallery, 2010. p. 7-28.

Didi-Huberman, G. Um conocimiento por el montaje. Entrevistado por P. Romero. Revista Minerva, Madrid: Círculo de Bellas Artes, v. 5, p. 17-22, 2007. Disponível em: <http://goo.g1/HA0Xs6>. Acesso em: 25 jun. 2016.

. O que vemos, o que nos olha. São Paulo: Editora 34, 2010.

. Diante da imagem. São Paulo: Editora 34, 2013.

Ducan, C. The esthetics of power in modern erotic art. Heresies, New York: Heresies Collective, n. 1, p. 46-50, jan. 1977. Disponível em: <goo.gl/rkfGg4>. Acesso em: 25 jun. 2016.

Fernandes, W; Siqueira, V. Cinema e relações de gênero: ouvindo mulheres idosas. In: Reunião Anual da ANPED, 29., 2006, Caxambu. Anais... Caxambu: ANPEd, 15-18, out. 2006. p. 1-13. Disponível em: <http://29reuniao.anped.org.br/trabalhos/ trabalho/GT23-2327--Int.pdf>. Acesso em: 20 nov. 2014.

Ferreira, M; Nunes, G; Klumb, M. As temáticas gênero e sexualidade nas reuniões da ANPEd de 2000 a 2006. Revista Brasileira de Educaşão, Rio de Janeiro: ANPEd; Campinas: Autores Associados, v. 18, n. 55, p. 899-1062, out.-dez. 2013. Disponível em: <goo.gl/rHwaqh>. Acesso em: 20 nov. 2014.

Foucault, M. História da sexualidade v. 1: a vontade de saber. Rio de Janeiro: Graal, 1988.

. Michel Foucault, uma entrevista: sexo, poder e a política da identidade. In: . Ditos E escritos $I X$ : genealogia da ética, subjetividade e sexualidade. Rio de Janeiro: Forense Universitária, 2014. p. 251-263.

Friedan, B. Mistica feminina. Petrópolis: Editora Vozes, 1971.

Lauretis, T. Alice doesn't: feminism, semiotics, cinema. Bloomington: Indiana University Press, 1984.

Loponte, L. Sexualidades, artes visuais e poder: pedagogias visuais do feminino. Revista Estudos Feministas, Florianópolis: UFSC, v. 10, n. 2, p. 283-300, ago.-dez. 2002. Disponível em: <goo.gl/dfdM3V >. Acesso em: 12 nov. 2013.

Louro, G. Pedagogias da sexualidade. In: O corpo educado. Belo Horizonte: Autêntica, 2003. p. 07-34.

. Gênero e sexualidade: pedagogias contemporâneas. Pro-Posiçôes, Campinas: UNICAMP, v. 19, n. 2, p. 17-23, maio-ago. 2008. Disponível em: <goo.gl/3d9btq>. Acesso em: 10 out. 2012. 
Martins, A. P. Visóes do feminino: a medicina da mulher nos séculos XIX e XX. Rio de Janeiro: Editora Fiocruz, 2004.

. O poder da benevolência: a participação das mulheres nas políticas sociais do Estado Novo brasileiro. 2011. (Projeto de Pesquisa) - Universidade Federal do Paraná, Curitiba.

Mendes, C. Quem pode resistir a Lara Croft? Você? Reunião Anual da ANPED, 28., 2005, Caxambu. Anais... Caxambu: ANPEd, 16-19, out. 2005. p. 1-16. Disponível em: <goo.gl/99Br8X>. Acesso em: 20 nov. 2014.

Meyer, D. Gênero e educação: teoria e política. In: Louro, G. L.; Neckel, J.; Goellner, S. Corpo, gênero e sexualidade: um debate contemporâneo na educação. Petrópolis: Vozes, 2003. p. 9-27.

. Gênero: re-constituir modos de pensar, ensinar e fazer em saúde e enfermagem. Congresso Brasileiro de Enfermagem, 56., 2004, Gramado. Anais... Gramado, 24-29, out. 2004. p. 1-6. Disponível em: <goo.gl/kVxlr1>. Acesso em: 23 fev. 2017.

NEAD, L. The female nude: pornography, art, and sexuality. Signs, Chicago: The University of Chicago Press, v. 15, n. 2, p. 323-335, Wint. 1990. <https://goo.gl/ zRL5Rm> Acesso em: 25 jun. 2016.

Nochlin, L. Why have there been no great women artist? In: . Women, art, and power. Boulder and Connor Hill: Westview Press, 1988a. p. 136-144.

. Eroticism and female imagery in nineteenth-century art. In: Women, art, and power. Boulder and Connor Hill: Westview Press, 1988b. p. 145-178.

Parker, R.; Pollock, G. Old mistresses: women, art, and ideology. New York: Pantheon Books, 1981.

Pereira, M. Gênero, sexualidade e infância: nas telas do cinema, a criança como sujeito do amor romântico. In: Reunião Anual DA ANPED, 33., 2010, Natal.Anais... Natal: ANPEd, 17-20, out. 2010. p. 1-15. Disponível em: 〈goo.gl/7vuJTL〉. Acesso em: 20 nov. 2014.

Pollock, G. Differencing the canon: feminist desire in the writing of art's histories. London/New York: Routledge, 2003.

Ribeiro, C.; Xavier Filha, C. Trajetórias teórico-metodológicas em 10 anos de produção do GT 23 da Associação Nacional de Pós-Graduação e Pesquisa em Educação - ANPEd. Revista Periódicus, v. 1, n. 2, Salvador: UFBA, p. 01-19, abr. 2015. Disponível em: <goo.gl/imOKzh>. Acesso em: 14 fev. 2017.

.; Siqueira, V. Construindo a masculinidade hegemônica: acomodações e resistências a partir da apropriação de personagens de novelas por adolescentes das camadas populares. In: Reuniño Anual da ANPED, 28., 2005, Caxambu. Anais... Caxambu: ANPEd, 16-19, out. 2005.p. 1-18. Disponível em: <goo.gl/B4laa2 >. Acesso em: 20 nov. 2014.

Roveri, F. A boneca Barbie e a educação de meninas - um Mundo de Disfarces. In: Reunião Anual da ANPED, 30., 2007, Caxambu. Anais... Caxambu: ANPEd, 7-10, out. 2007. p. 1-12. Disponível em: <goo.gl/pMdRc>. Acesso em: 20 nov. 2014. 
Sabat, R. Educar para a sexualidade normal. In: Reunião Anual da ANPED, 27., 2004, Caxambu. Anais... Caxambu: ANPEd, 21-24, nov. 2004. p. 1-12. Disponível em: <goo.gl/tVA4bs>. Acesso em: 20 nov. 2014.

Schwengber, M. As imagens e a educação generificada dos corpos. In: Reunião Anual da Anped, 36., 2013, Caxambu. Anais... Goiânia: ANPEd, 29-02, set.-out. 2007. p. 1-13. Disponível em: <goo.g1/1F7BKW>. Acesso em: 20 nov. 2014.

Scott, J. Os usos e abusos do gênero. Projeto História, n. 45, p. 327-351, dec. 2012. Disponível em: <goo.g1/9gI2rS >. Acesso em: 03 maio 2013.

Soares, R. Fica Comigo - juventude e pedagogias amorosas/sexuais na MTV. In: Reuniño Anual da ANPED, 29., 2006, Caxambu. Anais... Caxambu: ANPEd, 15-18, out. 2006. p. 1-18. Disponível em: 〈goo.gl/XGxDC〉. Acesso em: 20 nov. 2014.

Steiner, W. Venus in exile: the rejection of beauty in 20th-century art. Chicago: Chicago University Press, 2002.

\section{SOBRE OS AUTORES}

Gregory da Silva Balthazar é doutorando em educação pela Universidade Federal do Rio Grande do Sul (UFRGS).

E-mail: gsbalthazar@gmail.com

Fabiana de Amorim Marcello é doutora em educação pela Universidade Federal do Rio Grande do Sul (UFRGS). Professora na mesma instituição.

E-mail: famarcello@gmail.com

Recebido em 6 de março de 2017 Aprovado em 19 de junho de 2017 